\title{
Compliance with aseptic precautions during intravenous access among the nursing staff at the National Hospital of Sri Lanka (NHSL)
}

\author{
VR Bataduwaarachchi, M Balasubramanium, D Balasooriya, LDJU Senerath \\ Department of community medicine, Faculty of medicine, University of Colombo, \\ Kinsey road, Colombo, Sri Lanka.
}

doi: 10.3396/ijic.V7i3.021.11

\begin{abstract}
Intravenous access is one of the most commonly performed invasive procedures in the clinical practice, during which the improper practice of the aseptic precautions could lead to fatal healthcare associated infections. A descriptive cross sectional study was conducted to assess the compliance with aseptic precautions during intravenous access and to identify the determinants of the substandard practice and practical difficulties encountered at the National Hospital of Sri Lanka using a self administered questionnaire and an observational check list. The majority (60.2\%) of the participants fell in to the 'substandard' practice category. Compliance for the accepted method of hand washing was $8.4 \%$. Compliance was significantly better among the nursing students $(\mathrm{P}=0.001)$, nursing staff that had less experience $(\mathrm{P}=0.001)$ and who had updated their knowledge recently $(\mathrm{P}=0.043)$. The work overload $(95.2 \%)$ and the shortage of equipment $(65.1 \%)$ were the main practical difficulties identified. Hand washing practice should be further encouraged in the hospital setting. Continuing education and provisions of the necessary equipment are equally important.
\end{abstract}

Key words

Aseptic precautions, intravenous access, hand washing

\section{Corresponding author}

Dr. V. R. Bataduwaarachchi

Malwatta, Weihena, Baddegama, Galle, Sri Lanka.

Telephone number: +940775518470

Email: vipbat7@yahoo.com

Fax: +94 0112691581 


\section{Introduction}

Aseptic precautions are precautionary methods followed in any procedure where there is a possibility of introducing microorganisms into the patient's body. To some extent, the details of the aseptic techniques vary from one centre to the other, but they are similar in principle. ${ }^{1}$ Improper practice of aseptic precautions could lead to healthcare associated infections in the hospital setting. Previous studies have shown that at least $40 \%$ of primary bacteraemias in intensive care unit patients are associated with intravascular catheters. ${ }^{2}$ Prevention of these infections has a major positive impact on the total inhospital morbidity and mortality as well as the economy of the hospital. Despite the guidelines developed in most countries, compliance with aseptic precautions is known to be internationally suboptimal. ${ }^{3}$ One reason for the poor practice would be that since it is hard to pinpoint an actual time or event that causes an infection, nurses are unlikely to become involved in litigation. ${ }^{4}$ It is said that health care workers are more cautious and tend to follow the aseptic precautions during complex procedures (e.g. epidural catheterization, lumbar puncture) and in special settings such as operating theatres. But the proper practice of aseptic technique is not solely isolated to the operation theatre; it has a place in every clinical setting. ${ }^{5}$ Intravenous access is one of the commonly performed invasive procedures in the clinical practice to fulfil a variety of purposes including administration of intravenous (IV) drugs, setting up of infusions and blood transfusions, etc. Peripheral intravenous cannulae are the most commonly used intravascular catheter in the hospitals. ${ }^{6}$ Most of the previous studies focused on standard/universal precautions and limited data is available regarding the practice of aseptic precautions.

The objective of our study was to assess the compliance with aseptic precautions by the nursing staff during IV access and to identify the determinants of the substandard practice. This would be useful for the administrative sector of the hospitals to plan their activities including policy making and the staff training. Implementation of simple interventions would improve the proper practice of aseptic precautions thereby preventing the transmission of infections and minimizing the risk to the patients.

\section{Methods}

We conducted a descriptive cross sectional study involving the nursing staff attached to all the general medical and surgical wards including the casualty wards at the National Hospital of Sri Lanka (NHSL), which is one of the largest teaching hospitals in the region with more than 1000 beds. A convenience sample was taken to avoid the repetition of the same participant on two occasions. The wards were visited randomly and the nursing staff performing IV access were selected systematically from each ward during the visits. To assess the steps of the aseptic precautions, a checklist was ticked by an investigator after observing the procedure. A self administered questionnaire was answered by the relevant participant to assess the attitudes, perceptions and the other determinants towards the practice of aseptic precautions such as the work experience, age, job category, etc. The steps in aseptic precautions were taken from the National Guideline that is based on the World Health Organization protocol. The questionnaires with incomplete and incompatible answers were removed from the sample to maintain the accuracy. The SPSS version 17 software package was used for the statistical analysis. Frequencies were obtained for the steps of the aseptic technique and a scoring system was developed to assess the level of practice. The differences were further investigated by cross tabulations and the Chi-square test. This study was approved by the Ethics Review Committee of the Faculty of Medicine, University of Colombo.'

\section{Results}

A total of 96 participants were recruited for the study. The final sample taken for analysis was 83 due to the non response rate of $13.5 \%$. The majority of the sample represented female nursing officers $(60.24 \%)$ and most of the procedures were observed in the general medical wards (44.6\%).

\section{Compliance with the hand washing was not satisfactory}

All the participants at different ward settings were analyzed together and each step of the aseptic precautions was studied in detail (table I). The compliance with hand washing was not satisfactory among the participants, which was not done at all before and after the IV access by $59 \%$ and $83.1 \%$ respectively. Most of the participants complied well with the disinfection of the skin $(90.4 \%)$. Interestingly, only $1.2 \%$ of the participants followed the all steps 
Table I. Frequency distribution of the compliance with the steps of the aseptic precautions among the nursing staff

\section{Steps of the aseptic precautions followed during intravenous access (based on the National guidelines)}

\section{Number of participants}

Percentage $(\%)$

\begin{tabular}{|c|c|c|c|}
\hline \multirow{3}{*}{$\begin{array}{l}\text { 1. Hand washing before the } \\
\text { procedure }\end{array}$} & a. With soap and water & 7 & 8.4 \\
\hline & b. With water only & 27 & 32.5 \\
\hline & c. Not done at all & 49 & 59.0 \\
\hline \multirow[t]{3}{*}{ 2. Wiping of the hands } & a. With a clean towel & 5 & 6.0 \\
\hline & b. With a used towel & 25 & 30.1 \\
\hline & c. Not done at all & 53 & 63.9 \\
\hline \multirow[t]{3}{*}{ 3. Use of gloves } & a. New clean pair & 55 & 66.3 \\
\hline & b. Previously used pair & 4 & 4.8 \\
\hline & c. Not used at all & 24 & 28.9 \\
\hline \multirow{3}{*}{$\begin{array}{l}\text { 4. Disinfection of the injection } \\
\text { site }\end{array}$} & a. With $70 \%$ alcohol & 75 & 90.4 \\
\hline & b. With normal saline & 7 & 8.4 \\
\hline & c. Not done at all & 1 & 1.2 \\
\hline \multirow[t]{2}{*}{ 5. After the disinfection } & a. Allowed to dry & 69 & 83.1 \\
\hline & b. Wiped off & 14 & 16.9 \\
\hline \multirow[t]{2}{*}{ 6. Application of the dressing } & a. A sterile dressing was applied & 45 & 54.2 \\
\hline & b. Not applicable & 38 & 45.8 \\
\hline \multirow{2}{*}{$\begin{array}{l}\text { 7. Hand washing after the } \\
\text { procedure }\end{array}$} & a. Was done & 14 & 16.9 \\
\hline & b. Was not done & 69 & 83.1 \\
\hline
\end{tabular}

correctly. Each step of the procedure was given a score according to the level of practice (e.g. hand washing with soap and water: 10 marks; with water only: 5 marks; not done at all: 0 marks). The entire sample was divided into two groups based on the cut off mark of 40 out of 70 marks allocated for the complete correct procedure. The majority of the participants fell in to the 'substandard' group $(60.2 \%)$ compared to the 'satisfactory' group of $39.8 \%$ (table I).

\section{Adherence to aseptic precautions} was better among who are less experienced

Selected characteristics of the sample were assessed in relation to the 'substandard' and 'satisfactory' categories of the participants (table II). Adherence to the aseptic precautions was significantly better $(p=0.001)$ among the student nurses (66.66\%) compared to the nursing officers $(26.78 \%)$. Furthermore, among the 
Table II. Selected characteristics of participants in relation to the level of practice of aseptic precautions

Selected Charateristics

Level of practice according to the marks

Test

out of 70

statistics

Satisfactory

Substandard

Total

$(>40)$

$(<40)$

\begin{tabular}{|c|c|c|c|c|c|}
\hline \multirow{2}{*}{$\begin{array}{l}\text { 1. Age } \\
\text { category }\end{array}$} & a. $\leq 30$ years & $25(40.32 \%)$ & $37(59.67 \%)$ & 62 & \multirow[t]{2}{*}{$p=0.857$} \\
\hline & b. $>30$ years & $8(38.09 \%)$ & $13(61.90 \%)$ & 21 & \\
\hline \multirow[t]{2}{*}{ 2. Gender } & a. female & $30(41.66 \%)$ & $42(58.33 \%)$ & 72 & \multirow[t]{2}{*}{$p=0.364$} \\
\hline & b. male & $3(27.27 \%)$ & $8(72.72 \%)$ & 11 & \\
\hline \multirow[t]{2}{*}{ 3. Category } & a. nursing officer & $15(26.78 \%)$ & $41(73.21 \%)$ & 56 & \multirow[t]{2}{*}{$p=0.001$} \\
\hline & b. student nurse & $18(66.66 \%)$ & $9(33.33 \%)$ & 27 & \\
\hline \multirow[t]{2}{*}{ 4. Experience } & a. $\leq 5$ years & $21(60 \%)$ & $14(40 \%)$ & 35 & \multirow[t]{2}{*}{$p=0.001$} \\
\hline & b. $>$ 5years & $12(25 \%)$ & $36(75 \%)$ & 48 & \\
\hline \multirow[t]{4}{*}{ 5. Setting } & a. medical ward & $17(45.94 \%)$ & $20(54.05 \%)$ & 37 & \multirow[t]{4}{*}{$p=0.142$} \\
\hline & b. surgical ward & $10(43.47 \%)$ & $13(56.52 \%)$ & 23 & \\
\hline & c. medical casualty & $2(13.33 \%)$ & $13(86.66 \%)$ & 15 & \\
\hline & d. surgical casualty & $4(50 \%)$ & $4(50 \%)$ & 08 & \\
\hline \multirow[t]{5}{*}{ 6. Purpose } & a. for IV infusion & $13(35.13 \%)$ & $24(64.86 \%)$ & 37 & \multirow[t]{5}{*}{$p=0.369$} \\
\hline & b. for IV drug & $2(40 \%)$ & $06(60 \%)$ & 05 & \\
\hline & $\begin{array}{l}\text { c. blood for } \\
\text { investigations }\end{array}$ & $10(43.47 \%)$ & $13(56.52 \%)$ & 23 & \\
\hline & d. blood for culture & $4(30.76 \%)$ & $9(69.23 \%)$ & 13 & \\
\hline & e. blood transfusion & $04(80 \%)$ & $1(20 \%)$ & 05 & \\
\hline \multirow{2}{*}{$\begin{array}{l}\text { 7. Update of } \\
\text { Knowledge }\end{array}$} & a. with in past 6 months & $13(29.54 \%)$ & $31(70.45 \%)$ & 44 & \multirow[t]{2}{*}{$p=0.043$} \\
\hline & b. not in past 6 months & $20(51.28 \%)$ & $19(48.71 \%)$ & 39 & \\
\hline
\end{tabular}

nursing staff with less than five years experience $(60 \%)$, the practice of aseptic precautions was significantly better $(p=0.001)$ compared to the group who had more experience $(25 \%)$.

Additionally, the compliance was significantly better $(p=0.043)$ among nursing staff who had updated their knowledge $(51.28 \%)$ regarding aseptic precautions during previous six months compared to those that did not $(29.54 \%)$.

\section{Majority of the nursing staff perceived that correct} aseptic technique was practiced

Even if almost all the participants agreed that they had learned the steps of aseptic precautions during their training period, only 39 (53.01\%) had updated their 
knowledge within the previous six months. However, $81(97.6 \%)$ of the participants were aware that patients are exposed to an unnecessary risk of infection by failing to practice the correct aseptic technique. The majority of the nursing staff $(67.5 \%)$ perceived that aseptic precautions have always been followed by them during IV access. There is a difference of $66.3 \%$ between the self-reported compliance and their actual practice.

\section{Work overload was the main barrier for the proper practice of the aseptic precautions}

The majority of the participants $80(96.4 \%)$ stated that difficulties are encountered during the practice of aseptic precautions. Work overload was the main difficulty for most of them $79(95.2 \%)$. The shortage of equipment needed for the proper practice of aseptic precautions was a difficulty for $59(65.06 \%)$ of the participants including the lack of clean gloves 44 (53.01\%) and antiseptic solutions 40 (48\%). Lack of proper guidance was a problem for $13(16.45 \%)$ of the participants. With regards to the publication of the National guidelines of Sri Lanka, only 50 (60.2\%) of the participants were aware of its existence. However, $27(32.5 \%)$ of the participants had seen it and 14 $(16.9 \%)$ of them had read it at least once. Interestingly, $29(35.8 \%)$ of the participants revealed that the failure of other members of the healthcare team to adhere to the aseptic precaution is a barrier for them to practice the proper method.

\section{Discussion}

Intravenous access is one of the most commonly performed invasive procedures in the hospital setting. Improper practice of aseptic precautions during IV access can lead to healthcare associated infections that can be fatal. The results of our study show that hand washing practice was not satisfactory among the nursing staff. It is the most effective measure for interrupting the transmission of micro-organisms which cause infection in the healthcare setting. But compliance with hand hygiene recommendations is poor worldwide. ${ }^{8}$ It is known to have a positive interrupting effect; even in unsanitary environments such as diarrheal wards. ${ }^{9}$

The poor compliance with hand washing, which is vital in preventing the transmission of infections between patients, could contribute to rapid spread of healthcare associated infections in the hospital setting. Compared to hand washing, usage of the clean gloves was better among the nursing staff. This is in agreement with a study conducted in United Kingdom, which identified an emerging glove culture and continuing poor hand-hygiene practices. ${ }^{10}$ Use of gloves does not replace hand-washing due to potential contamination of glove surfaces, leaks, and the creation of a favourable environment for bacterial growth. ${ }^{11}$ Improvement of hand hygiene compliance will require changing healthcare workers behaviour towards glove use. According to our results, a used pair of gloves was worn by $4.8 \%$ of the participants. Failure to change or remove the contaminated gloves carries a high-risk of microbial transmission. ${ }^{12}$

Considering the determinants of substandard practice, adherence to aseptic precautions was significantly better among the nursing students, nursing staff with less than five years experience and those who had updated their knowledge recently. These findings indicate that recent exposure to the education is an important contributor to good practice. Even if almost all participants had learned the steps of the aseptic precautions during their training period, our study emphasizes the importance of updating knowledge.

Furthermore, there was a significant variation between the self reported compliance and the actual practice. This finding is quite similar to that of the study on the practice of Universal precautions conducted in Thailand which revealed that $85.5 \%$ of nurses were knowledgeable on universal precautions but only $27.9 \%$ of them reported to taking precautions with all patients. ${ }^{13}$ We believe the above variation between attitudes and practices could be due to lack of knowledge, ignorance, and the practical difficulties. Even though the majority of the participants (65.1\%) stated that shortage of equipment is encountered during the practice of aseptic precautions, no special equipment is required for simple hand washing. Therefore the compliance should have been better with the hand washing which showed very low compliance. This highlights the importance of changing the attitudes and misconceptions of the healthcare workers to improve correct practice.

The failure of the other members of the healthcare team to adhere to the aseptic precautions was a 
barrier for the others to practice the proper method. This indicates the need of equal implementation of policies for all the members of the health care team. Our results showed that nursing staff were reluctant to refer to the booklet of National Guideline during the busy ward schedule. This indicates the necessity of a more feasible approach such as displaying posters/ stickers with simple instructions at the nursing stations in addition to the booklet.

Our conclusion is that the hand washing practice in the hospital setting should be encouraged and development of more practical solution should be further explored. Updating of knowledge and provision of the necessary equipment are equally important to improve the compliance with the aseptic precautions.

\section{Acknowledgement}

We would like to thank the director of the National Hospital of Sri Lanka and all the participants of the study.

\section{References}

1. Crows L. Asepsis the right touch, 1st ed. Bossier City: Everett co-operation 1989; 279-280.

2. Elliott TST, Faroqui MH, Armstrong RF. Guideline for good practice in central venous catheterization. Journal of Hospital Infections 1994; 28: 163-164. http.dx.doi. org/10.1016/0195-6701(94)90100-7

3. Gammon J, Morgen H. A review of the evidence for suboptimal compliance of health care practitioners to infection control precautions. Journal of Clinical Nursing 2007; 17: 157-167.

4. Preston RM. Aseptic technique: evidence-based approach for patient safety. Br J Nurs 2005; 14(10): 540-542.

5. Schraag J. Applying aseptic technique in all clinical settings: Infection control today 2006.

http://www.infectioncontroltoday.com. (Accessed April 20, 2010).

6. Adreas F, Wenzel RP. Prevention and control of nosocominal infections, 2nd ed. London: Elsevier Limited 2000; 123-125.

7. Forum for ethics review committees in Sri Lanka: ERC Colombo. http://www.fercsl.net/erccolombo.html (Accessed September 22, 2010).

8. Akyol A, Ulusoy H, Ozen I. Hand washing to prevent diarrhea in day-care centers. American Journal of Epidemiology 1981; 113: 445.

9. Khan MU. Interruption of shigellosis by hand washing. Trans. Royal Soc. Trop. Med. \& Hygiene. 1982; 76(2): 164-168. http.dx.doi.org/10.1016/0035-9203(82)90266-8

10. Gould JD, Chudleigh N, Drey D. Measuring hand washing performance in health service audits and research studies Journal of Hospital Infection 2007; 66(2): 109-115. http. dx.doi.org/10.1016/j.jhin.2007.02.009

11. Guzewich J, Ross MP. Interventions to prevent or minimize risks associated with bare hand contact with ready to eat food: Hygenius 1999. http://www.hygenius.com (Accessed March 23, 2010).

12. Girou E, Chai S H, Oppein F, et al. Misuse of gloves: the foundation for poor compliance with hand hygiene and potential for microbial transmission? Journal of Hosp Infections 2004; 57(2): 162-169. http.dx.doi.org/10.1016/j. jhin.2004.03.010

13. Danchaivijitr S, Tantiwatanapaiboon Y, Chokloikaew S, Tangtrakool T, Suttisanon L, Chitreechuer L. Universal precautions, knowledge, compliance and attitudes of doctors and nurses in Thailand. Journal of Medical Association in Thailand 1995; 78(2): 112-117. 